MATEC Web of Conferences 33, 03020 (2015)

DOI: $10.1051 /$ matec conf/ 20153303020

(c) Owned by the authors, published by EDP Sciences, 2015

\title{
Microstructural effects of strain aging on NiTi pseudoelastic wires by synchrotron X-ray micro-diffraction
}

\author{
Antonio Isalgue ${ }^{1, a}$, Carlota Auguet ${ }^{1}$, Amadeu Concustell $^{2}$ and Nuria Cinca ${ }^{2}$ \\ ${ }^{1}$ Dep. Física Aplicada, Universitat Politecnica Catalunya (UPC) Pla Palau 18, 08003 Barcelona, Spain \\ ${ }^{2}$ CPT - Dep. CMEM, Facultat de Química, Universitat de Barcelona, Diagonal 645, 08028 Barcelona, Spain
}

\begin{abstract}
In this work, we explore the consequences of strain aging pseudoelastic NiTi wires (2.46 mm diameter) at moderate temperatures $\left(100^{\circ} \mathrm{C}\right)$. The changes of the stress-strain behaviour on aged, as compared with non-aged wires, with comparatively smaller changes in thermal transformation, indicate the existence of relevant strain fields on these wires. The fact that thinner wires perform differently on aging suggests the possibility of radial dependence of the strain fields. Measurements were performed at CELLS-ALBA synchrotron, BL04 Materials Science Powder Diffraction beam-line. X-ray micro-diffraction for near $10(\mu \mathrm{m})^{2}$ (FWHM) zones on cross-sections of samples was done, aiming to detect residual strains as function of radial position on the wire. The results show very small changes of diffraction peaks position, with more relevant variations near the surface. This might be interpreted as a high sensitivity of the transformation on stresses enabling defined paths of transformation..
\end{abstract}

\section{Introduction}

The SMA's work is based on a martensitic transformation: a first-order phase transformation with hysteresis, between meta-stable phases, which involves release and absorption of latent heat, besides a shape change [1]. Because of its singular thermomechanical properties, the SMA's are also considered functional smart materials [2]. The particular properties of SMA suggest their use as actuators, via Shape Memory Effects, or as dampers, using the hysteresis to convert mechanical vibrations to thermal energy. To reach appropriate reliability for applications as damper, mechanical properties have to be known and understood. Due to its thermo-mechanical properties, NiTi alloy has been suggested as material for damping in civil engineering [38]. In fact, among the SMAs, NiTi alloy is the most studied and used [9]

Pseudoelastic NiTi wires with the same composition and transformation temperature but different diameter have been shown to perform differently $[10,11]$, then here we look for microstructure effects on different diameter (radius) wires.

\section{Experimental}

NiTi alloy in the pseudo-elastic state, furnished by Memry (CT, USA), a division of SAES Getters (Italy), and previously, by Special Metals Corp. (New Hartford, New York, USA). We used straight-annealed wires of $2.46 \mathrm{~mm}$ diameter and $0.5 \mathrm{~mm}$ diameter that had Ni-rich composition (55.95 wt \% Ni, balance Ti). The As

\footnotetext{
${ }^{a}$ Corresponding author: antonio.isalgue@upc.edu
}

temperature measured by DSC was $237 \mathrm{~K}$. The wires were in the light oxide surface state as furnished.

Mechanical cycling was done by means of MTS 810 testing machine, in an air-conditioned room. Speed of cycling was $100 \mathrm{~s}$ per cycle for the $2.46 \mathrm{~mm}$ diameter wire, and $20 \mathrm{~s}$ for the $0.5 \mathrm{~mm}$ diameter wire, in order to achieve similar conditions concerning the heat transfer characteristic times to the ambient. The strain aging has been done with the help of devices as described in [10], aging of a wire strained to $7.8 \%$ has been done for 1 month in a furnace at $100^{\circ} \mathrm{C}$. Thin disks $(0.3 \mathrm{~mm})$ were cut with a low speed diamond saw from the $2.46 \mathrm{~mm}$ diameter wires to perform diffraction experiments.

Synchrotron radiation from ALBA was used to perform micro-diffraction experiments at room temperature, $25^{\circ} \mathrm{C}$ (Cerdanyola del Valles, Spain; beamline BL04, 2013110801 experiment on MSPD@ALBA). The wavelength used was 0.4246 A, the beam was of near $10 \mu \mathrm{m}^{2}$ (FWHM), and a CCD detector of 2048 sections was used, each element ("pixel") of the detector was of 79 by $79 \mu \mathrm{m}$. The detector was situated at $260.5 \mathrm{~mm}$ of the samples with angular resolution between measured points corresponding to near around $0.01^{\circ}$ in two-theta. In this way 4 rings (peaks) could be registered, corresponding to the cubic beta phase of NiTi. All the samples produced only the cubic beta phase peaks. The raw data was processed with the software FIT2D [12] to obtain the diffraction along a given direction, with $\mathrm{a}+/-5^{\circ}$ integrating margin in angle around a given direction along the "cake" of data. By checking the shape of peaks from a $\mathrm{Si}$ powder sample, it could be observed some distortion of the peaks shapes' obtained in the vertical

This is an Open Access article distributed under the terms of the Creative Commons Attribution License 4.0, which permits unrestricted use distribution, and reproduction in any medium, provided the original work is properly cited 
direction of diffraction, attributable to imperfect curvature of the monochromator used. Then, we analyze here only diffraction in the horizontal direction, and compare results for different samples. Table 1 gives the position of diffraction peaks, the indexing and the observed intensities, from the as furnished $2.46 \mathrm{~mm}$ diameter wire cut sample. The cell parameter was 3.013 A, in agreement with [13].

The mounting allowed controlled displacements of the samples in the vertical and horizontal direction, perpendicular to the X-ray beam incidence, enabling scanning of the micro-diffraction samples. For the 2.46 $\mathrm{mm}$ diameter wire cut disks, the length direction of the wire (in the $0.3 \mathrm{~mm}$ disk thickness direction) was put parallel to the X-ray beam, and scan in the horizontal diameter was performed. The thin $0.5 \mathrm{~mm}$ diameter wire was set in the vertical, allowing for scans in the horizontal direction traversing the wire.

Table 1. Position, indexation and intensity of observed diffraction peaks for the as furnished material.

\begin{tabular}{|c|c|c|}
\hline $\begin{array}{c}\text { Peak } \\
\text { position } \\
\text { (two theta) }\end{array}$ & $\begin{array}{c}\text { Miller indices } \\
\text { (hkl) }\end{array}$ & $\begin{array}{c}\text { Observed } \\
\text { intensity (au) }\end{array}$ \\
\hline $8.080^{\circ}$ & 100 & 40 \\
\hline $11.436^{\circ}$ & 110 & 4600 \\
\hline $14.016^{\circ}$ & 111 & 20 \\
\hline $16.190^{\circ}$ & 200 & 130 \\
\hline
\end{tabular}

The (100) and (111) peaks had a very low intensity in all the patterns (see figures 3 and 4), visible from the synchrotron X-ray arrangement and detector high signal to noise ratio.

\section{Results and Discussion}

The strain aging at moderate temperatures as $100^{\circ} \mathrm{C}$ produces remarkable changes in the stress-strain cycles of NiTi pseudoelastic wires. The observations show that the strain aging produces different changes in wires of different diameters, even when the wires have the same composition and transformation temperatures [11], see figures 1 and 2 . For the $2.46 \mathrm{~mm}$ diameter wire, after aging, the mechanical cycle at room temperature extends to a larger stress span, giving also the possibility to extend the interval of working temperatures for damping [14]. However, for the $0.5 \mathrm{~mm}$ diameter, the wire is not able to retransform to beta phase at room temperature on unloading (figure 2). The dependence on radii of the strain aging actions done on the pseudoelastic wire suggest looking for structural differences that might exist due to the straight annealing performed by the furnisher of the wires.

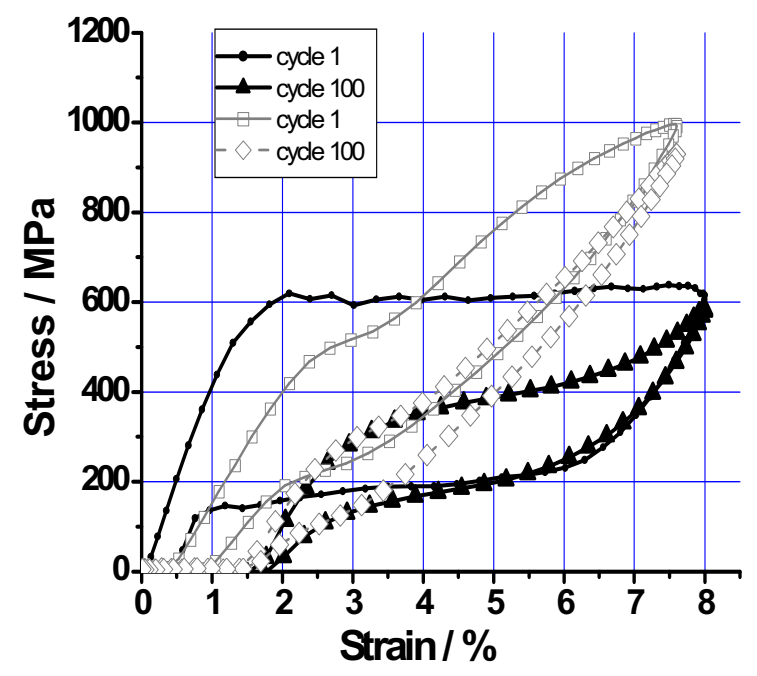

Figure 1. Stress aging effect on $2.46 \mathrm{~mm}$ diameter NiTi wire. Cycle 1 (continuous line), as furnished wire, and cycle 100 (triangles). Strain aged wire, cycles 1 (discontinuous, with squares) and 100 (with diamonds). With diamonds: cycle 100.

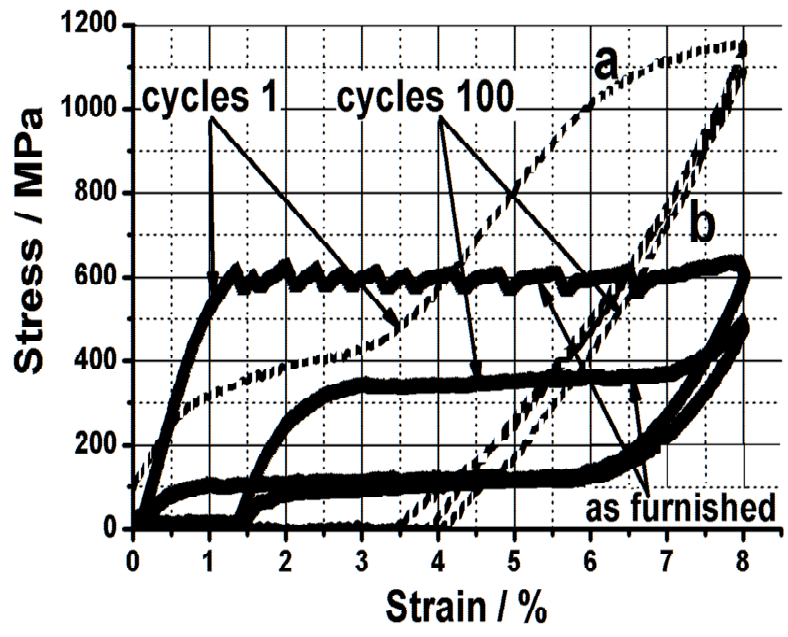

Figure 2. Stress aging effect on $0.5 \mathrm{~mm}$ diameter NiTi wire: As furnished wire, continuous line (cycles 1 and 100, at lower stress to retransform). Aged wire, dashed line (a: cycle 1; b: cycle 100).

Micro-diffraction experiments were done looking for structural differences among points in the samples (near the centre of the wire or nearer to the end in the diameter direction) on the samples. The grain size had been determined previously to be less than 0.1 micrometer [14]. The results of the direct measure with the Debye (transmission) geometry are as shown in figure 3 , where two rings can be detected by eye. The time including movement of the sample and data acquisition and transfer was 24 s per explored sample point. The beam stop has been also marked in the figure 3 , and the zone has been excluded from data treatment. 


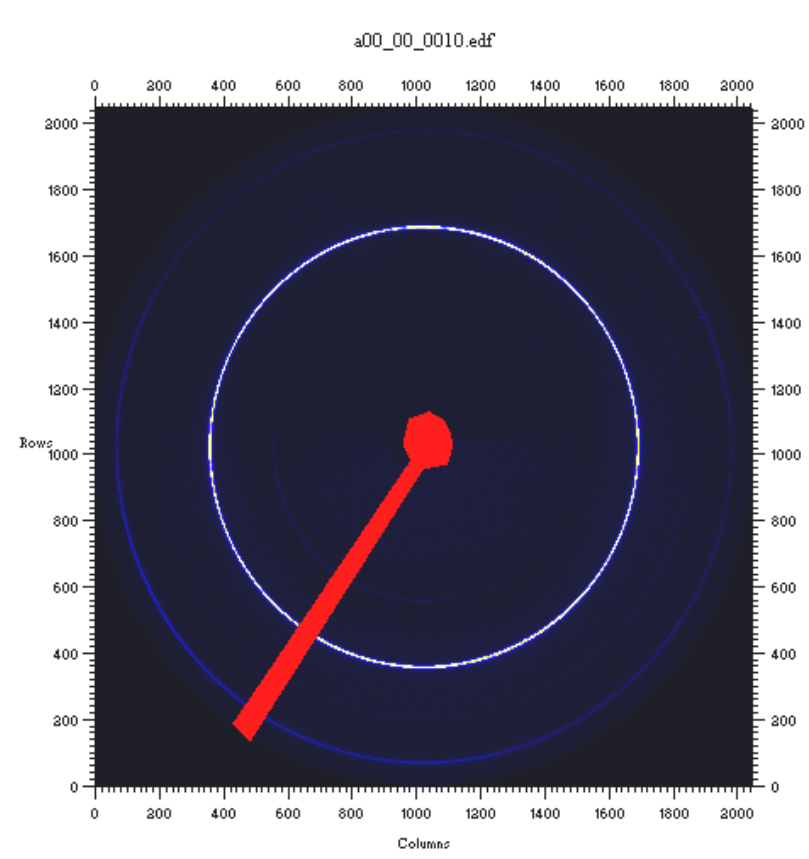

Figure 3. 2-D result of the diffraction for the as-furnished sample (2.46 $\mathrm{mm}$ diameter), near the center of the wire. The two more intense peaks, (110) and (002) can be directly seen.

Averaging over the $+/-5^{\circ}$ around the horizontal direction with the help of FIT2D software gives results (diffractograms) as shown in figure 4, for the asfurnished material (from the data in figure 3 ).

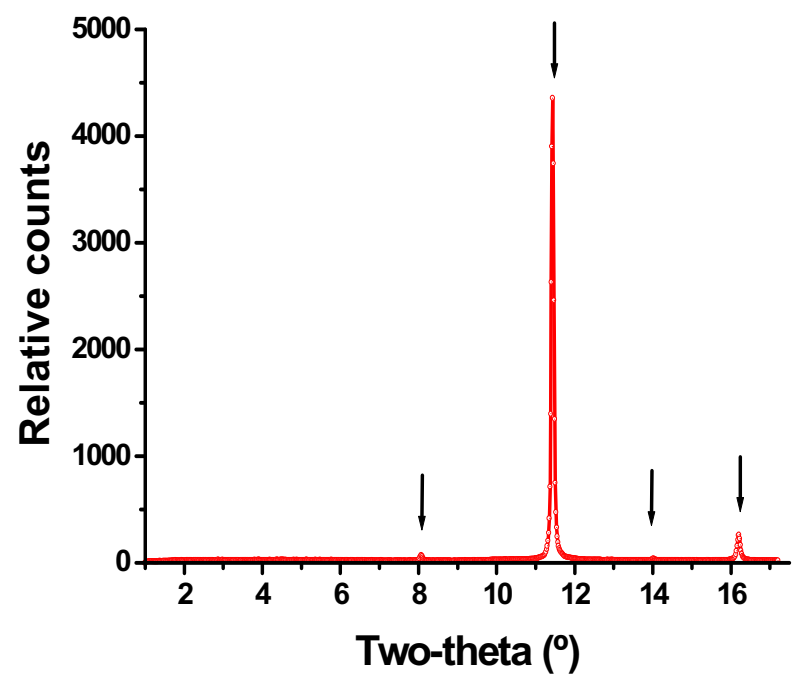

Figure 4. Obtained diffractogram in the horizontal direction, for the as-furnished wire, near the center of the wire. The arrows indicate the four detected peaks.

The short number of peaks measured, the texture which had been detected in the wires [14], the resolution and the statistics prevented using a full diffractogram fit (Rietveld-type) to the NiTi structure including strain effects on peak positions and widths. The two larger peaks $((110)$ and (200)) were individually fitted to pseudo-Voigt functions, to detect possible crystallographic changes from one point to the other.

For the as-furnished $2.46 \mathrm{~mm}$ diameter wire, the width of the larger peak (110) shows a nearly constant value along the diameter, with a very slight increase near the border of the sample (see figure 5). The diffraction angle, two-theta, shows also nearly constancy, and a very slight increase near the diameter border of the sample was detected (see figure 6). These effects were also found for the (200) diffraction peak (figures 7 and 8).

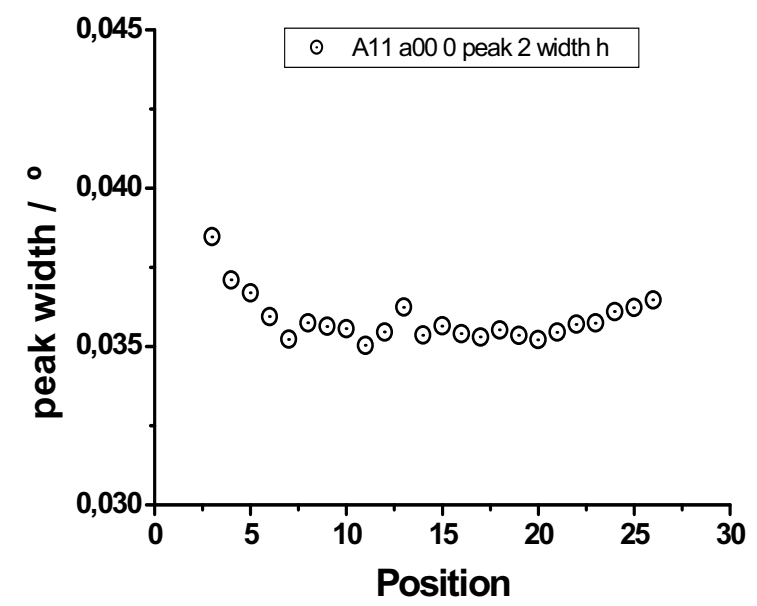

Figure 5. Width of the (110) peak as function of position (in number of spectra) in the diameter direction of the as-furnished $2.46 \mathrm{~mm}$ diameter wire section (position step between points, $100 \mu \mathrm{m})$.

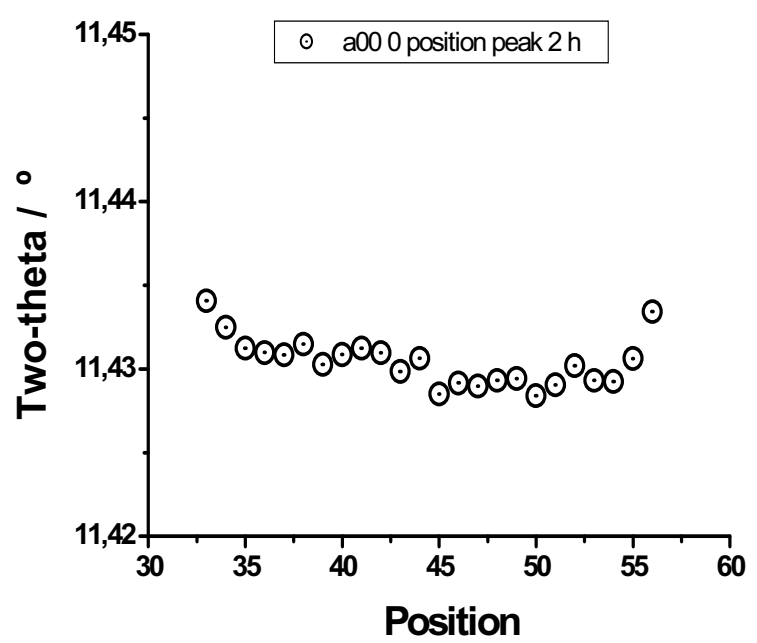

Figure 6. Two theta angle of the (110) peak as function of position in the diameter direction of the as-furnished wire section (position step between points, $100 \mu \mathrm{m}$ ).

The experiment was done also with the as furnished $0.5 \mathrm{~mm}$ diameter wire, with position steps of $50 \mu \mathrm{m}$, and the wire set in vertical position, so as the movement of the sample produced the diffraction spot travelled the sample wire from side to side. In this case, the conditions are different from the $2.46 \mathrm{~mm}$ diameter wire. Here the diffraction spectra corresponding to near the centre of the wire include contribution from the interior of the wire but also from the lateral surface of the wire. The results showed also a very slight increase of line width and two theta angles near the lateral surface of the sample (figures 9 and 10). 


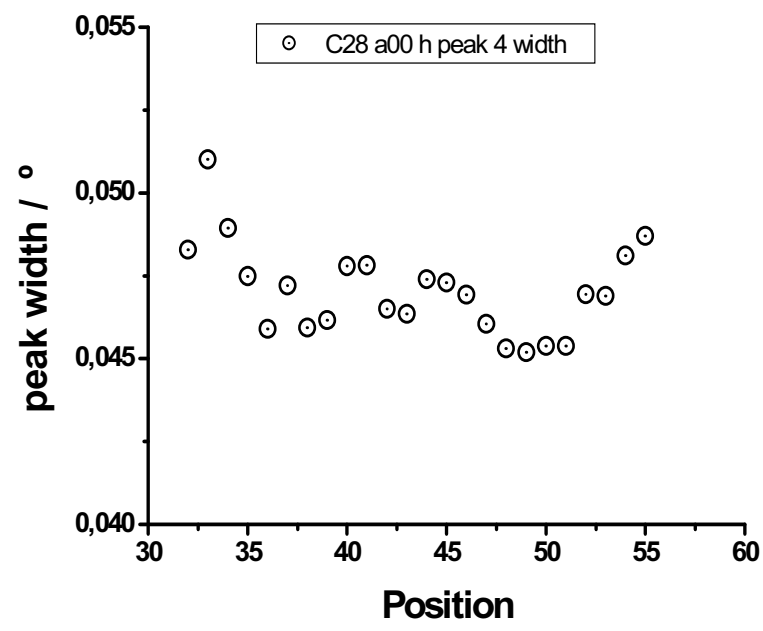

Figure 7. Width of the (200) peak as function of position in the diameter direction of the as-furnished wire section (position step between points, $100 \mu \mathrm{m}$ ).

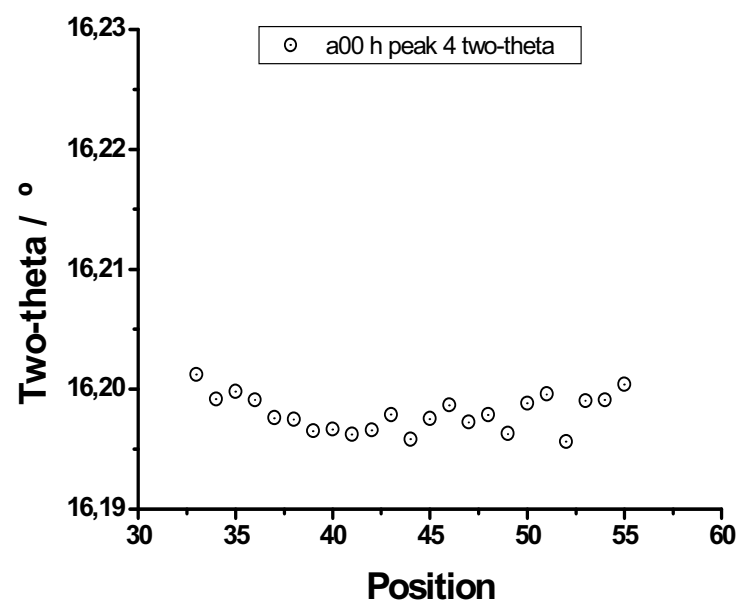

gure 8. Two theta angle of the (200) peak as function of position in the diameter direction of the as-furnished wire section (position step between points, $100 \mu \mathrm{m}$ ).

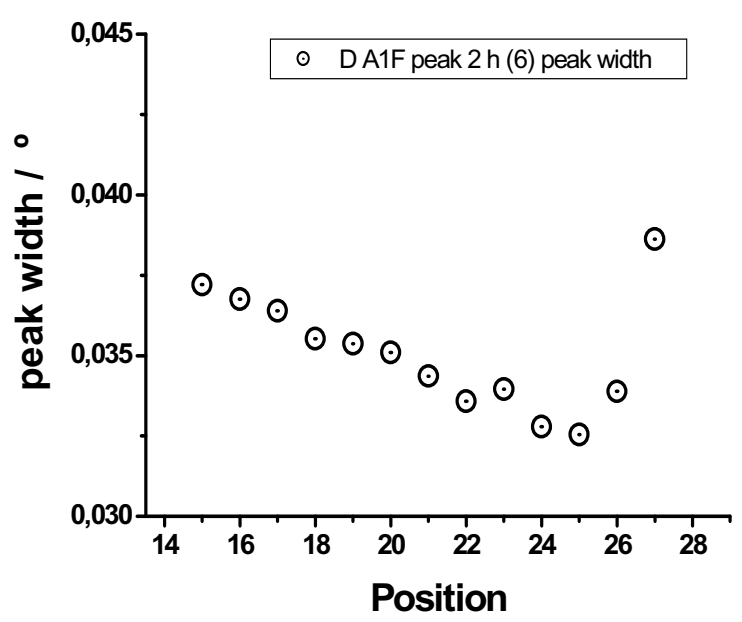

Figure 9. Two theta angle of the (110) peak as function of position in the diameter direction of the as-furnished $0.5 \mathrm{~mm}$ diameter wire section (position step between points, $50 \mu \mathrm{m}$ ).

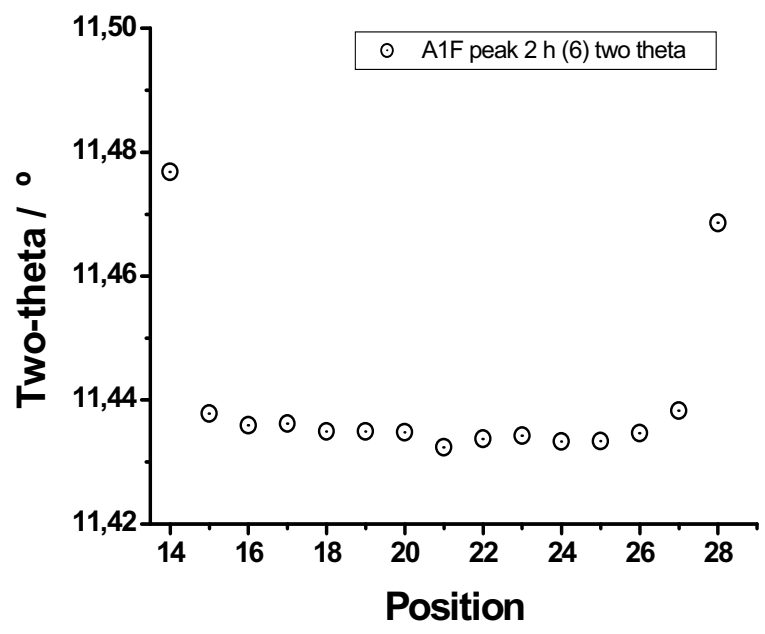

Figure 10. Two theta angle of the (110) peak as function of position in the diameter direction of the as-furnished $0.5 \mathrm{~mm}$ diameter wire section (position step between points, $50 \mu \mathrm{m}$ ).

A $2.46 \mathrm{~mm}$ diameter wire sample was strained to $7.8 \%$ and then aged at $100^{\circ} \mathrm{C}$ in a furnace during 1 month. The aged sample was analyzed in a similar way as the as furnished sample. The measured line width near the end of the sample in the diameter direction was higher (see figures 11 and 13), with enlargements clearly higher than the as furnished wire sample.

The enlargement of peaks width at the surface, for the as-furnished sample, was in the $0.05^{\circ}$ margin, while the enlargement near the external surface of the wire for the aged sample was around $0.2^{\circ}$. The position of the main peaks resulted also slightly modified (see figures 12 and 14).

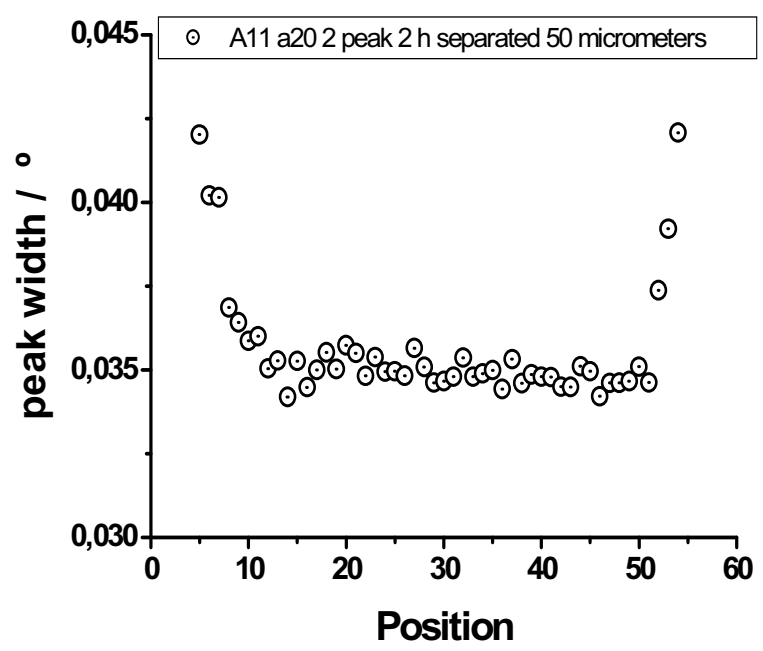

Figure 11. Width of the (110) peak as function of position in the diameter direction of the strain-aged wire section (position step between points, $50 \mu \mathrm{m}$ ). 


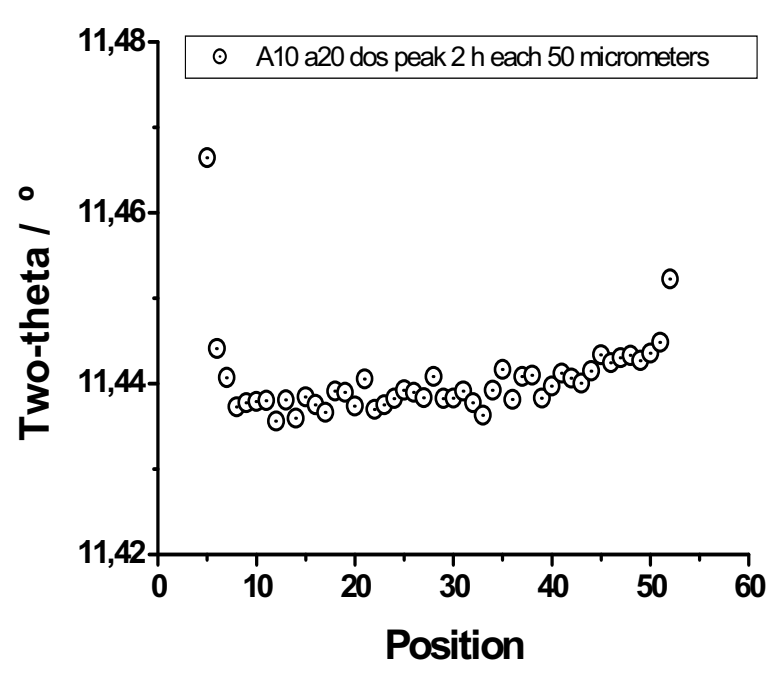

Figure 12. Two theta angle of the (110) peak as function of position in the diameter direction of the strain-aged wire $(2.46$ $\mathrm{mm}$ diameter) (position step between points, $50 \mu \mathrm{m}$ ).

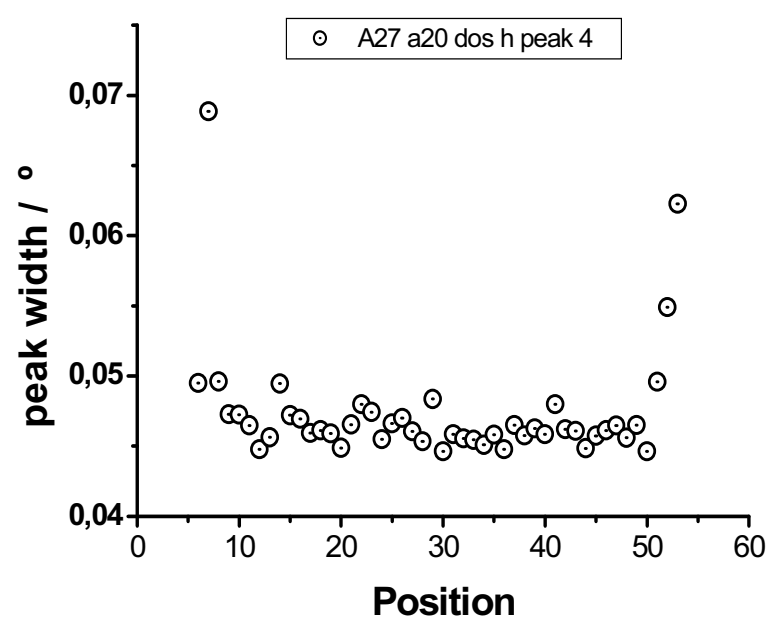

Figure 13. Width of the (200) peak as function of position in the diameter direction of the strain-aged wire section (position step between points, $50 \mu \mathrm{m}$ ).

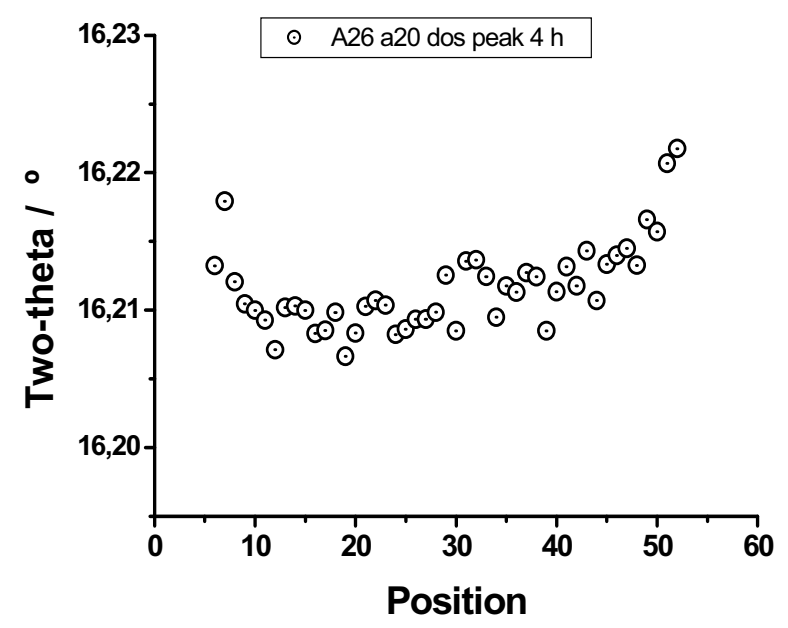

Figure 14. Two theta angle of the (200) peak as function of position in the diameter direction of the strain-aged wire $(2.46$ $\mathrm{mm}$ diameter) section (position step between points, $50 \mu \mathrm{m}$ ).
Positioning of the samples could influence the small diffraction angle differences between the wires (as furnished and aged). If disks surfaces were not perpendicular to the X-ray beam, distance sampledetector could be slightly different from one point of the sample to another, affecting in first place to peak position. However, the increase of peak width at the extremes of the samples should not be strongly influenced by positioning, and this peak width increase near the surface is much larger for the strain-aged sample.

This implies a wider stress distribution inside the aged sample, near the surface of the wire. The origin of this wider residual stress is in the stress aging process, that first strains the material to near completion of martensitic transformation at room temperature (some $600 \mathrm{MPa}$, see figure 2), and then, the increase of temperature to $100^{\circ} \mathrm{C}$ (from room temperature) would imply, via the ClausiusClapeyron equation for these wires [15], a near $500 \mathrm{MPa}$ stress increase.

At the GPa level of stress, some plasticity starts to appear (see stress-strain curve to fracture in figure 2 of [16]), and on unloading, the martensite retransforms to beta due to the low transformation temperatures, but plastic deformation leaves a stress distribution and a high density of dislocations, which originate also in the transformation [17].

The asymmetry of the zones near the surface of the wire, which is covered by a thin oxide layer, and has mechanical imperfections (defects) near $10 \mu \mathrm{m}$ size [16], produces a larger (wider) stress distribution there, after transforming-retransforming, showing the observed "diameter effect" on the behaviour of the wires.

\section{Conclusions}

Microstructural effects of strain aging at $100^{\circ} \mathrm{C}$, on NiTi pseudoelastric wires, have been looked for by microdiffraction performed at ALBA-CELLS synchrotron radiation utility.

The results of the measurements show that, on strain aged sample, the width of the diffraction peaks increase appreciably near the surface of the wires.

This effect might be understood as the result of the high stresses and some plastic deformation during the strain aging, leaving a wider distribution of residual stresses near the surface of the wires. This wider stress distribution near the surfaces exists after the strain aging because the existence of imperfections (mechanical defects) and oxide on the surface, which act as a source of non-symmetric stresses on transforming.

\section{Acknowledgements}

The support from Spanish MICINN is acknowledged. Also, thanks are given to the staff at ALBA-CELLS BL04 (MSPD) beam-line for assistance and help with the micro-diffraction experiments. 


\section{References}

1. K. Otsuka and C.M. Wayman, editors. Shape memory materials, (Cambridge University Press, Cambridge, 1998)

2. C.M. Wayman: Shape Memory Alloys. MRS Bull. 18 49-56 (1993)

3. V. Torra, A. Isalgue, F. Martorell, P. Terriault, F.C. Lovey. Eng. Structures 29 1889-1902 (2007)

4. O. E. Ozbulut, S. Hurlebaus, R. DesRoches. J. of Intel. Mater. Systems and Struct. 22 1531-1549 (2011).

5. V. Torra, C. Auguet, A. Isalgue, G. Carreras, P. Terriault, F.C. Lovey. Eng. Structures 49 43-57 (2013)

6. A. Isalgue, C. Auguet, G. Carreras, V. Torra: Functional Materials Letters, 5 (1) 1250008 (4 pages) (2012).

7. V. Torra, A. Isalgue, FC. Lovey, M. Sade. J Therm Anal Calorim 119:1475-1533 (2015).

8. C. Maletta, E. Sgambitterra, F. Furgiuele, R. Casati, A. Tuissi. Int. Journal of Fatigue 66, 78-85 (2014).

9. K. Otsuka, X. Ren. Progress in Mater. Sci. 50, 511678 (2005)

10. V. Torra, C. Auguet, A. Isalgue, G. Carreras, FC. Lovey: J Therm. Anal. Calorim. 112:777-780 (2013).

11. C. Auguet, A. Isalgue, V. Torra, G. Carreras, F.C. Lovey. "Effects of strain aging in NiTi SMA wires for dampers". International Conference on Martensitic Transformations 2014, Bilbao, Spain (2014).

12. www.esrf.eu/computing/scientific/FIT2D/ (January 2015).

13. http://www.memry.com/nitinol-iq/nitinolfundamentals/physical-properties (May 2015).

14. V. Torra, A. Isalgue, C. Auguet, G. Carreras, FC. Lovey, P. Terriault, P. Can. Metall. Quarterly, 52 (1) 81-89 (2013).

15. A. Isalgue, V. Torra, A. Yawny, and F.C. Lovey. J. Therm. Anal. Calorim. 91 (3), 991-998 (2008)

16. A. Isalgue, V. Torra, F. Casciati, S. Casciati: "Fatigue of NiTi for dampers and actuators". CIMTEC 2012 Montecatini Terme, Italy, June 2012. Series: EMBODYING INTELLIGENCE IN STRUCTURES AND INTEGRATED SYSTEMS. Advances in Science and Technology 83, 18-27 (2013)

17. T. Simon, A. Kroger, C. Somsen, A. Dlouhy, G. Eggeler. Acta Materialia 58:1850-1860 (2010) 